\title{
An Effective Card Game for Conflict Resolution Between Nurses and Patients
}

Mayumi Uno ${ }^{\star}$, Shinko Fujinaga and Yukari Nishio

Faculty of Nursing, Shijonawate Gakuen University, Daito, Osaka 574-0001, Japan

Abstract

Background: Conflict in interpersonal relationships is strongly tied with emotional affectedness, and emotional changes are associated with conflict. An effective response to conflicts requires experience in conflict resolution. Based on game theory, the authors devised a card game as an educational and training intervention to provide conflict experience. This study aimed to create a prototype of a card game effective for practicing conflict resolution between nurses and patients and discovering beneficial solutions during conflict between the two parties.

Methods/Results: From the existing 144 conflict scenarios, 60 were extracted and analyzed from the perspective of patient reactions. Four core categories were thus created: "Furious," "Dissatisfied," "Disappointed," and "Other." The "Other" category comprised the following subcategories- "Responsible party," "Distrust," "Personal information," "Difference in sensibility," "Dissatisfaction," and "Self-determination." The authors thus developed an intriguing card game that they have named "Conflict: Between Nurses and Patients."

Conclusion: The card game is expected to provide beneficial solutions for both nurses and patients as well as the basis for trainee nurses and patients to express their emotions in face-to-face encounters. The nurse-patient card game can be used in intervention research. As the card game is based on data from clinical experiences of nurses and counselors, it will contribute to the development of communication among nurses. It will also enhance the conflict-resolution ability of both nurses and patients.

\section{Introduction} response to different types of conflict requires years of experience
Trust-based relationships with patients are crucial to the foundation of quality nursing. The word "trust" is derived from an old term denoting loyalty and piety, however, the phenomenon itself is even older [1]. Although it is difficult to clearly define the relationships of trust between nurses and patients from the literature [2-5], Hupcey et al. [6] reported that patients' trust in nurses is an essential factor for establishing effective connections between nurses and patients; however, if a conflict arises between the two parties, trust can be damaged and the quality of nursing in terms of patient perception scan deteriorate if appropriate measures are not taken.

\section{Conflict}

Conflict has been empirically investigated for a long time in psychology, sociology, and other fields. Robbins [7] defines conflict as a process that begins when one recognizes that others have adversely affected something important to that person or are about to do so. Conflict in interpersonal relationships is strongly tied with emotional affectedness, and emotional changes are associated with conflict. In other words, if emotional elements relating to conflict are ignored and a response to the conflict is centered on rationality and logic, the conflict cannot be resolved effectively. It is therefore important to detect a patient's emotions during conflict at an early stage and take appropriate measures [8], as well as to find a solution that is beneficial to both the nurse and the patient by taking advantage of the opportunity represented by the conflict $[9,16]$.One of the conditions for an appropriate response to conflict is "conflict experience." An effective [10], as well as an educational intervention equal to those years of experience. As an educational intervention, the authors proposed creating simulated conflict scenarios into a game from which conflict experiences could be gained. The game also includes a training element for finding solutions that are beneficial to both nurses and patients by taking advantage of the opportunity represented by conflict.

\section{Role of game theory}

According to Okada [11], game theory is used to analyze the behaviors and decisions of multiple players and can serve as a strategy for identifying confrontations and optimal solutions. The structure of games is defined as sharing the basic and common characteristics of society. Game theory includes several frameworks, such as "choice and decision-making, strategy, Nash equilibrium, conflict and cooperation, moral hazards, negotiations, group formation, and sharing of benefits."Integrating these various methodologies, game theory presupposes players to be autonomous decision-makers; it is an academic discipline that aims to form a better society based on cooperation among individuals $[12,13]$.

Based on these interpretations, the authors considered it preferable to utilize game theory to respond to conflict between nurses and patients by adding the concept of communication to the "conflict and cooperation" framework. While playing the devised game, the two parties have the opportunity to assert their own opinions while respecting each other's ideas, even amid conflict. Thus, the authors devised a game that allows players to learn to perceive the thoughts of others from amid simulated conflict through training and assert oneself while accepting the opinions of others. For this purpose, the authors utilized a card game because in such face-to-face encounters, people can work together to find effective solutions for both parties by expressing their emotions in real-time within the framework of a game that is easy to play.

"Corresponding Author: Dr. Mayumi Uno, Faculty of Nursing, Shijonawate Gakuen University, Daito, Osaka 574-0001, Japan; E-mail: unomayu@gmail.com

Citation: Uno M, Fujinaga S, Nishio Y (2021) An Effective Card Game for Conflict Resolution Between Nurses and Patients. Int J Nurs Clin Pract 8: 336. doi: https:// doi.org/10.15344/2394-4978/2021/336

Copyright: (c) 2021 Uno et al. This is an open-access article distributed under the terms of the Creative Commons Attribution License, which permits unrestricted use, distribution, and reproduction in any medium, provided the original author and source are credited. 


\section{Objective}

The study aimed to develop a prototype of a card game effective for conflict-resolution between nurses and patients, with the goal of finding solutions beneficial to both sides while taking advantage of the opportunity represented by the conflict.

\section{Methods}

\section{Development of the card game}

\section{Data collection}

Existing data from the principal researcher's doctoral dissertation thesis were utilized for obtaining information on perceptions of suffering from nurses and patients and were used for the construction of an effective interactive model [9].

A descriptive survey of 320 first-level nurses was conducted in an annual nursing manager workshop organized by a local professional nursing association. This sample was selected as these nurses were likely to have gained the care giving experience suitable for the survey and be able to effectively verbalize their experiences.

For the survey of the patients, we interviewed them directly; however, as it was difficult to obtain such data, we also interviewed eight telephone counselors from a non-profit organization of nonmedical professionals located in the Osaka Prefecture, Japan. These counselors often received calls from patients who were unable to express their feelings directly to medical professionals. This sample was chosen because telephone counselors with a certain amount of training and experience communicate with patients about their feelings that is otherwise not conveyed to nurses.

\section{Data analysis}

From the obtained conflict scenarios (144), the authors carefully extracted scenarios suitable for the card game. They qualitatively analyzed and categorized the content of the conflict scenarios from the perspective of patient reactions into four categories; "Furious," "Dissatisfied," "Disappointed," and "Other."

\section{Making the cards}

The selected conflict scenarios were then edited into phrases and expressions that were easy to employ in a game format. On the back of the cards, the names of the core categories were indicated, along with color-coding. On the front of the cards, the authors indicated core category labels and the conflict scenarios, together with an illustration matching the conflict scenario. The illustrations used in the game were copyright-free materials obtained from Google search. The cards were of the playing-card size and were laminated to withstand disinfection with alcohol. Furthermore, a game board was developed to be placed between the players when playing the game, which would indicate whose turn it was to draw the conflict card.

\section{Ethical considerations}

Consent was obtained from the research collaborators to use the existing data from their study. This design of this research was approved by the research ethics review committee of the researchers' institution (Approval Number 2019003).

\section{Playing the card game}

1. A total of four to five people gather in one room and face each other in a circle.

2. The first player is decided mutually.

3. One person serves as the active player and the others are member players.

4. The active player draws one of the 60 items in the four categories of conflict cards."Furious Patient," "Dissatisfied Patient," "Disappointed Patient," and "Other."

5. The active player reads aloud the conflict scenario on the drawn card.

6. The active player verbally expresses how they interpreted the conflict scenario and how they would handle the situation.

7. The member player on the right of the active player expresses their opinion, such as "I like the idea" or "It might be better to do something a bit differently (such as ___ )." This continues in a circle. At this time, the players agree to convey their thoughts authentically so that others can understand their reasoning, and respect the ideas of the active player.

8. The active player says "Thank you," even if they are dissatisfied.

9. The active player for the next round is the last player of the current round.

10. The game is completed after each player gets a turn as an active player.

\section{Results}

A descriptive survey of nurses yielded 72 scenarios, and another 72 scenarios were extracted from interviews with specialists who worked as telephone counselors, resulting in a total of 144 conflict scenarios.

First, the authors extracted 60 conflict scenarios from the 144 that they evaluated to be applicable to an educational card game between nurses and patients. Next, by classifying the carefully extracted conflict scenario data from the viewpoint of "patient reactions," four core categories were created-"Furious," "Dissatisfied" "Disappointed," and "Other." Each classification consisted of 15 scenarios. The core category of "Other" consisted of the subcategories "Responsibility," "Distrust," "Personal information," "Difference in sensibility," "Dissatisfaction," and "Self-determination" (Table 1).

The core category was indicated and color-coded on the back of the cards. "Furious" was color-coded red, "Dissatisfied" was coded yellow, "Disappointed" was coded purple, and "Other" was coded white. On the front of the cards, the authors added an illustration matching the conflict scenario to the core category code and conflict scenario data.

The authors named the card game "Conflict: Between Nurses and Patients."

\section{Discussion}

\section{Anticipated intervention effects}

Through having players participate in the card game, we aimed to find solutions that are beneficial to both nurses and patients by taking the opportunity presented by conflict between the two parties. We believe that the effectiveness of the intervention can be assessed by 


\begin{tabular}{|c|c|c|}
\hline Categories & Subcategories & Conflict Scenario \\
\hline \multirow[t]{15}{*}{ Furious } & & $\begin{array}{l}\text { When returning to the ward at around } 21: 00 \text {, a young nurse said arrogantly, "You were sure gone a long time." Why } \\
\text { say that so rudely without first asking about my situation? }\end{array}$ \\
\hline & & $\begin{array}{l}\text { I asked you not to tell my parents about my medical stay! Today, my mother came to visit and told me she had heard } \\
\text { from the nurse about my condition! What is going on here? }\end{array}$ \\
\hline & & $\begin{array}{l}\text { My mother, who cannot move on her own, was taken to a common room in a wheelchair and was left there and } \\
\text { forgotten for about } 3 \text { hours! What's more, I heard about this from the patient in the bed next to hers! What is } \\
\text { happening? }\end{array}$ \\
\hline & & $\begin{array}{l}\text { Without saying anything to me, the nurse silently took the continuous passive motion device I was using for } \\
\text { rehabilitation, even though the practice session was not yet finished! Whatever for? }\end{array}$ \\
\hline & & $\begin{array}{l}\text { After gastric surgery, the nurse failed three times when trying to insert the IV drip! My surgery was difficult and } \\
\text { Iwanted a nurse to help me, but the nurse failed with the injection. Can she be considered competent? }\end{array}$ \\
\hline & & $\begin{array}{l}\text { Maybe the hospital feels like home, or something. But the nurse spoke to my father, who is more than } 80 \text { years old, } \\
\text { like she was speaking to a child! Unbelievable! }\end{array}$ \\
\hline & & $\begin{array}{l}\text { I was discovered in a pachinko parlor by the nurse on the nurse's day off. "Why did you tell on me nurse! "I cannot } \\
\text { trust the nurses anymore!" }\end{array}$ \\
\hline & & $\begin{array}{l}\text { My immune system is growing weaker during my steroid treatment! Nurses do not visit me following visits to other } \\
\text { patients to make sure I do not get infected! }\end{array}$ \\
\hline & & $\begin{array}{l}\text { The mother of a child patient requested: "We measure her urine volume at home, so I want the hospital to do the } \\
\text { same during her hospitalization." But the nurses do not do so because her medical condition doesnot require it. } \\
\text { Make the hospital like home! }\end{array}$ \\
\hline & & $\begin{array}{l}\text { I was asked by nurse A when trying to learn about my dietary intake, "How much did you chow down?" What the } \\
\text { heck?(This is so inappropriate) }\end{array}$ \\
\hline & & Why would a nurse open a box of dialysate with a box cutter! What if the box breaks? \\
\hline & & $\begin{array}{l}\text { I asked the nurse to change the direction that the bed is facing, but the nurse didnot pay any attention. This was } \\
\text { despite the fact that it is a private room. Why not? }\end{array}$ \\
\hline & & $\begin{array}{l}\text { When I came to the hospital from work, my child was still asleep, even though I told the staff to wake her up by } 3 \\
\text { o'clock! With that, my child won't fall asleep at night and our schedule will get disturbed! }\end{array}$ \\
\hline & & $\begin{array}{l}\text { I don't know if someone was hospitalized in the middle of the night, but when I was finally about to fall asleep, I } \\
\text { heard loud voices of nurses from near the hospital cafeteria. Why do they need to speak so loudly for such a long } \\
\text { time at such hours! }\end{array}$ \\
\hline & & $\begin{array}{l}\text { I was told by a nurse I never got along with, "Return to your room for an evacuation drill!" I said to her, "Why are } \\
\text { you the one telling me?" }\end{array}$ \\
\hline \multirow[t]{10}{*}{ Dissatisfied } & & $\begin{array}{l}\text { Visitors of patients in the room are noisy, and I am having trouble getting enough rest. The nurse pretends not to see } \\
\text { the problem. Can anything be done? }\end{array}$ \\
\hline & & $\begin{array}{l}\text { I finally became pregnant at the age of } 35 \text {. I can't help but feel uneasy because the pregnancy is going poorly. The } \\
\text { nurse says my situation is not a big deal, perhaps because she is accustomed to patients that are critically ill. The } \\
\text { nurse's senses are probably numb. }\end{array}$ \\
\hline & & $\begin{array}{l}\text { Loud laughter can be heard from the nurse station. Why? This is despite the fact that we patients are suffering so } \\
\text { much. }\end{array}$ \\
\hline & & $\begin{array}{l}\text { I was informed about a drug that will reduce my wife's level of consciousness at the end stage of her cancer. I asked } \\
\text { the doctor, "Is this euthanasia?" The nurse grinned and said, "Sedation." An unscrupulous response. }\end{array}$ \\
\hline & & $\begin{array}{l}\text { In the ICU after surgery, the nurse was speaking loudly, and even when I said "Please come see me; I am in pain," } \\
\text { the nurse didn't come immediately. That was awful. }\end{array}$ \\
\hline & & $\begin{array}{l}\text { I said we were there for my husband's rehabilitation, and the nurse said to me, "I will have him sit in a wheelchair for } \\
\text { three hours starting today." Her decision was completely unilateral; are my husband's wishes not important? }\end{array}$ \\
\hline & & $\begin{array}{l}\text { I called and explained the situation in detail on the telephone to undergo an emergency examination on a holiday, } \\
\text { but then I was asked to explain again from the beginning to the nurse who came on the line next. I was the one who } \\
\text { was sick, though. }\end{array}$ \\
\hline & & $\begin{array}{l}\text { I went to the hospital because of severe dizziness after an operation. The nurse said to me, "If it is this level of } \\
\text { dizziness, you can return home after the IV drip." I was hoping she would sympathize a bit more with my situation. }\end{array}$ \\
\hline & & $\begin{array}{l}\text { When I consulted with the head nurse about the bad attitude of the nurse in charge today, the head nurse responded } \\
\text { to me while sitting on the other side of the counter even though I was standing. What on earth is that attitude all } \\
\text { about? }\end{array}$ \\
\hline & & $\begin{array}{l}\text { After my operation, I was worried because my back still hurt. When I asked the nurse, "Please take me to the } \\
\text { bathroom in a wheelchair," I was told callously, "You should be able to do it yourself." That was harsh. }\end{array}$ \\
\hline
\end{tabular}




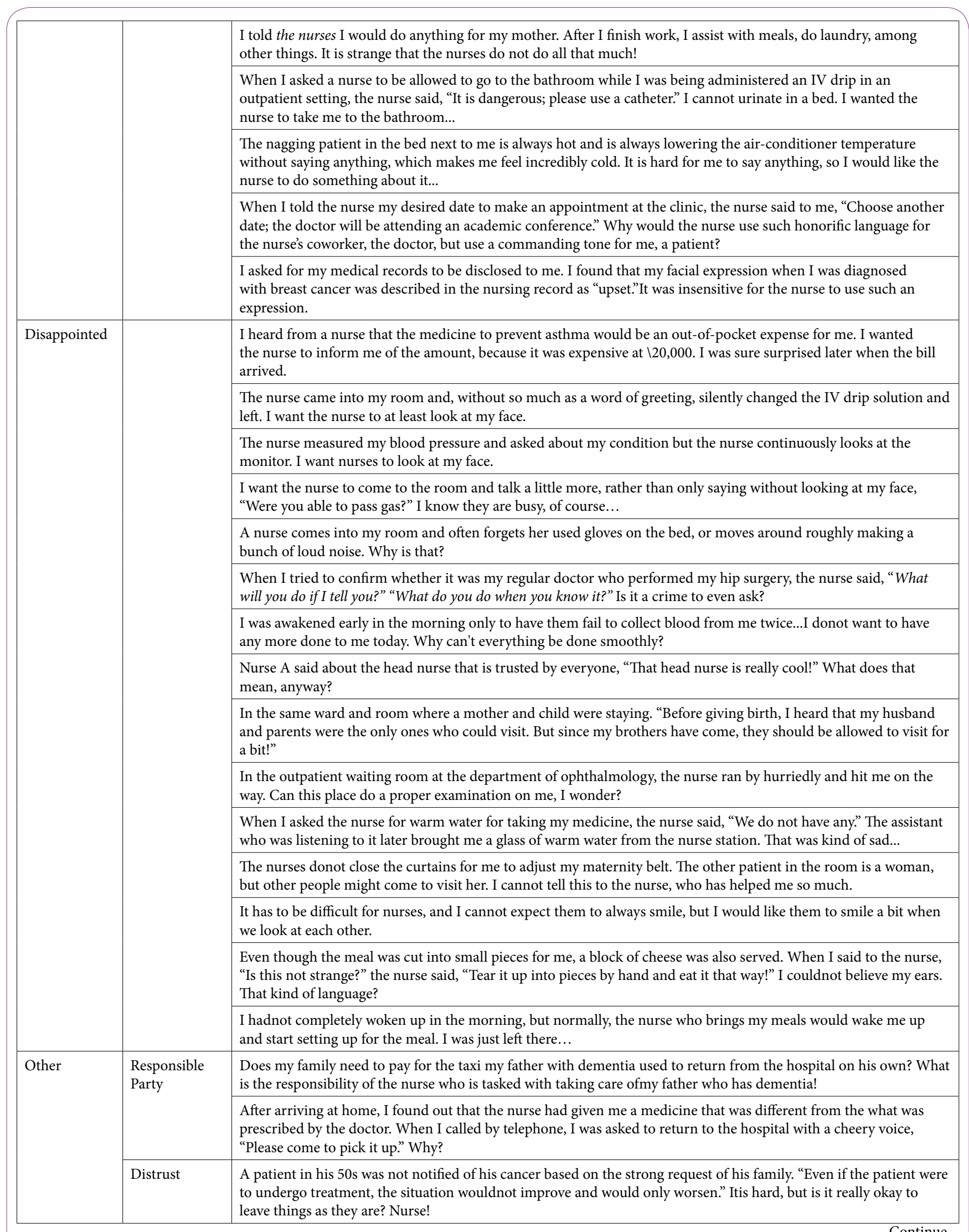






Table 1: Conflict scenarios between nurses and patients.

the Thomas-Kilmann Conflict Mode Instrument of types of conflictresponses, based on the theoretical framework laid out by Thomas [14]. Thomas's five different conflict-responsive styles are- i) Competing mode: an assertive and non-cooperative response approach; ii) Collaborating mode: an assertive and cooperative response approach; iii) Compromising mode: an assertive and cooperative intermediate response approach; iv) Avoiding mode: a response method that is neither assertive nor co-operative; and v) Accommodating mode: a non-assertive and cooperative response approach. The effectiveness of the game as a conflict-resolution intervention is indicated through a higher rate of selection of the collaborative mode, which offers the most assertive and cooperative response.

\section{Emotional expression through face-to-face games}

People are naturally sensitive to others' emotion-related facial expressions. Facial expressions are non-verbal information consciously or unconsciously transmitted and are tools for strengthening connections and relationships of trust between people. In a study among nursing students by Ekman and Friesen [15], facial expression stimulation was found to be an effective medium for transmitting nonverbal information using visual channels in interpersonal communication.

As such, it is considered that receiving information from facial expressions while multiple people react to a conflict scenario represents an experience of conflict between patients and nurses, who routinely read the other's emotions. A person's reaction is a good opportunity to identify what kind of facial expression (emotional expression) can be used to create a positive atmosphere in the group which the authors believe will serve as the basis for training. For these reasons, it is believed that playing this game face-to-face is useful.

\section{Advantages of playing simple games}

As card-games are compact, they can be enjoyed anywhere as long as there are tables and chairs. Moreover, additional conflict scenarios can be prepared while casually communicating with other players. The conflict scenarios used in this game were selected from reallife conflicts that arose in clinical practice most commonly. In other words, because the game employs familiar topics that elicit a response such as, "Yes, This is realistic," the players are likely to evaluate the scenarios as topics that might arise on a daily basis. However, as patient reactions in the conflict scenarios represent a window into the patients' true feelings, and as these feelings are rarely directly communicated to nurses, it makes this aspect of the game fresh and new. The authors believe that it is meaningful to have players easily experience simulated conflicts within the framework of a simple game.

\section{Conclusion}

The nurse-patient card game can be used in intervention research. As the card game is based on data from clinical experiences of nurses and counselors, it can contribute to the development of communication among nurses. The card game can enhance the conflict-resolution ability of both nurses and patients.

\section{Competing Interests}

The authors declare that they have no competing interests. 


\section{Author's contributions}

Dr. Uno was the principal investigator mainly responsible for planning, data collection, game design, card making, and paper authorship.

Dr. Fujinaga devised the game and made the cards, and revised and approved the paper.

Ms. Nishio devised the game, made the cards, and approved the paper.

\section{Acknowledgement}

This paper was presented at the $34^{\text {th }}$ Kinki-Hokuriku Regional Association of the Japan Academy of Nursing Research.

\section{Funding}

This study was supported by the Institute of Health Sciences, Shijonawate Gakuen University, grant number-IHSS1902.

\section{References}

1. Mollering G, Bachmann R, Lee SH (2004) Understanding organizational trust: foundations, constellations, and issues of operationalisation. J Manag Psychol 19: 556-570.

2. Doucet TJ (2008) Having faith: A Parse research method study. Nurs Sci 22 259-266.

3. McQueen A (2000) Nurse-patient relationships and partnership in hospital care. J Clin Nurs 9: 723-731.

4. Pask EJ (1994) Trust: an essential component of nursing practiceimplications for nurse education. Nurse Educ Today 15: 190-195.

5. Ramo H (2004) Moments of trust: temporal and spatial factors of trust in organizations. J Manag Psychol 19: 760-775.

6. Hupcey JE, Penrod J, Moorse JM (2002) An exploration and advancement of the concept of trust. J Adv Nurs 36: 282-293.

7. Robbins SP (2009) Organizational behavior. Diamond, Japan.

8. Uno M (2015) A study using SERVQUAL to evaluate trends in patient expectations when conflict arises. J Yamato University 1: 173-179.

9. Uno M (2018) Creation of a model of suffering and good interaction based on the perception of nurses and patients, doctoral dissertation, Osaka University.

10. Uno M (2016) Aspects of avoidance of conflict between nurses and patients, according to Japanese Gold Nurses (or Expert Nurses): A program for raising the quality of nursing. J Yamato University 2: 91-97.

11. Okada A (2020) Game theory for introduction to and understanding of human society. Yuhikaku Alma Publishing

12. Camerer CF, Ho TH (2015) Behavioral game theory experiments and modeling. Handbook of game theory with economic applications.

13. Osborne MJ (2004) An Introduction to Game Theory. Oxford University Press.

14. Thomas KW (2015) Introduction to Conflict Management. Japan Psychologists Press, Japan.

15. Ekman P, Friesen WV (1976) Measuring facial movement. Environmental psychology and nonverbal behavior. J Nonverbal Behav 1: 56-75.

16. Uno M (2018) The Concepts of "Patient Suffering" and "Favorable Interaction" in Nurse-Patient Conflicts Based on Gaps in Perception. Biomed J Sci Tech Res 2: 2235-2242. 